\title{
Patient activation for self-management is associated with health status in patients with atrial fibrillation
}

This article was published in the following Dove Press journal: Patient Preference and Adherence

\author{
Pamela J McCabe' \\ Lynette G Stuart-Mullen' \\ Christopher J McLeod ${ }^{2}$ \\ Thomas O Byrne ${ }^{3}$ \\ Monika M Schmidt ${ }^{2}$ \\ Megan E Branda ${ }^{3}$ \\ Joan M Griffin ${ }^{3,4}$
}

'Mayo Clinic Department of Nursing, Mayo Clinic College of Medicine and Science, Mayo Clinic, Rochester, MN, USA; ${ }^{2}$ Department of Cardiovascular Diseases, Mayo Clinic College of Medicine and Science, Mayo Clinic, Rochester, MN, USA; ${ }^{3}$ Robert D. and Patricia E. Kern Center for the Science of Health Care Delivery, Mayo Clinic, Rochester, MN, USA; ${ }^{4}$ Division of Healthcare Policy and Research, Mayo Clinic, Rochester, MN, USA
Correspondence: Pamela J McCabe Mayo Clinic Department of Nursing, Mayo Clinic College of Medicine and Science, Mayo Clinic PB 3-15, 200 First Street SW, Rochester, MN 55905, USA Tel +l 507293 I5I5

Email mccabe.pamela2@mayo.edu
Background: Higher levels of patient activation for self-managing health are associated with positive clinical and health care utilization outcomes. Identifying a patient's activation level can guide clinicians to tailor interventions to improve their health. Effective self-management of atrial fibrillation (AF) requires patient activation to participate in treatment decisions, prevent complications, and manage risk factors. Yet, little is known about activation in patients with AF. The purpose of this descriptive study was to identify patient activation levels and factors associated with activation in patients with AF.

Methods: Patients (N=123), 66\% male, with a mean (SD) age of 59.9 (11.3) years seeking treatment for AF at an arrhythmia clinic completed the Patient Activation Measure (PAM), Atrial Fibrillation Severity Scale, Knowledge about Atrial Fibrillation test, Hospital Anxiety Depression Scale, Godin Leisure-Time Exercise Questionnaire, and Patient Assessment of Chronic Illness Care. Sociodemographic and clinical data were obtained from medical records. PAM scores were categorized into Levels 1-4. Associations among patient-reported outcomes, sociodemographic, and clinical variables were analyzed using Fisher's exact tests and KruskalWallis procedures.

Results: The PAM scores of nearly half $(45.5 \%)$ of the patients were at Level 3, while the scores of $38 \%$ were at Level 4 . Male sex $(P=0.02)$, higher education $(P=0.004)$, being employed $(P=0.005)$, lower body mass index $(P=0.03)$, tobacco abstinence $(P=0.02)$, less AF symptom burden $(P=0.006)$, less depression $(P \leq 0.0001)$ and anxiety $(P=0.006)$, greater knowledge of AF $(P=0.01)$, and higher levels of physical activity $(P=0.02)$ were associated with higher activation levels.

Conclusion: Higher levels of patient activation in those with AF were associated with a more positive health status and educational attainment. Additional research to describe activation in patients with AF is warranted to identify patients at risk for low activation and to tailor interventions to activation level.

Keywords: atrial fibrillation, self-management, patient activation, patient engagement, chronic illness care

\section{Introduction}

Patient activation or engagement in managing their health is associated with positive clinical and health care utilization outcomes. ${ }^{1-3}$ Facilitating patients' acquisition of the knowledge, skills, and confidence to manage their health is critical in the current environment where $60 \%$ of adults live with one chronic illness, and $81 \%$ of those over 65 years have multiple chronic conditions that are manageable, but not curable. Ninety percent of health care spending goes to care for chronic illnesses. ${ }^{4}$ Approaches 
to chronic illness care such as risk factor management, prevention of complications, and maintaining optimal control are vital to optimizing quality of life and managing health care costs.

Patient activation has been defined as the state in which the individual possesses the knowledge, skills, and confidence to manage their health and health care. Hibbard et al conceptualize patient activation on a continuum in which patients can be categorized by levels of activation. ${ }^{5}$ Table 1 presents patient activation characteristics for each level. Higher levels of activation are associated with greater selfmanagement knowledge; ${ }^{2,6}$ medication adherence; ${ }^{2,3,7}$ better weight management; lower tobacco use; achievement and maintenance of hypertension, lipid, and glucose levels; ${ }^{8-10}$ psychological well-being; ${ }^{10-12}$ fewer emergency department visits, ${ }^{1,10}$ unplanned hospital visits; ${ }^{1,3,7,10}$ and discharges to skilled care. ${ }^{11}$ Through cognitive and behavioral interventions, patients can improve their level of activation. Upward movement is associated with improved clinical and health care utilization outcomes. ${ }^{3,10}$

Outcomes associated with improved patient activation have been documented across chronic illnesses such as diabetes, ${ }^{2}$ heart failure (HF), ${ }^{3,12}$ coronary artery disease, ${ }^{7}$ renal disease, ${ }^{12}$ and COPD. ${ }^{12}$ Atrial fibrillation (AF) is a chronic condition with increasing prevalence that requires patient activation to engage in shared decision making to choose among multiple treatment options for AF, prevent complications, and manage multiple risk factors that contribute to disease progression and recurrence. ${ }^{13}$ Hospitalizations for AF have increased markedly and costs for AF treatment have soared. ${ }^{14}$ Recent reports suggest that improving selfmanagement of risk factors for AF such as hypertension, lipids, obesity, elevated blood glucose, and increasing physical activity plays an important role in stemming progression of AF and are associated with lower costs for AF-related care. ${ }^{15-17}$ Langseth et al reported that engaging in shared decision making for treatment options resulted in lower treatment costs. ${ }^{18}$

Activating patients to be partners in their management of AF has been recognized as an essential practice in recent guidelines for AF management. ${ }^{13}$ Yet little is known about patient activation in patients with $\mathrm{AF}$ and factors that are associated with patient activation in this population. Knowledge about patients' current level of activation and the factors associated with activation are important for shared decision making and care planning. By identifying the level of activation, tailored interventions can be developed to improve activation among those with low levels or strengthen and maintain activation among those with higher levels. Clinicians can develop a practical and patient-centered plan to move the patient up the activation continuum. ${ }^{5}$ The purpose of this retrospective cross-sectional study was to describe patient activation levels in patients with symptomatic AF and determine if patient-reported (AF symptom burden,

Table I Characteristic of patients for levels of activation and score ranges of the levels in the PAM as described by Hibbard ${ }^{5,10}$

\begin{tabular}{|c|c|c|}
\hline $\begin{array}{l}\text { Level of } \\
\text { activation }\end{array}$ & $\begin{array}{l}\text { Recommended } \\
\text { PAM score range }\end{array}$ & Characteristics \\
\hline Level I & $0-47.0$ & $\begin{array}{l}\text { Passive, sees the provider as decision maker } \\
\text { Does not take accountability for health outcomes } \\
\text { Lacks knowledge about the condition and recommended self-care activities } \\
\text { Adherence is poor } \\
\text { Lacks confidence for self-management }\end{array}$ \\
\hline Level 2 & $47.1-55.1$ & $\begin{array}{l}\text { Possesses some knowledge about the condition and recommended self-care, but large gaps are present } \\
\text { Lacks confidence for self-management } \\
\text { Sees health outcomes as outside of their control } \\
\text { Able to set simple short-term goals }\end{array}$ \\
\hline Level 3 & $55.2-72.4$ & $\begin{array}{l}\text { Possesses requisite knowledge about the condition and recommended self-care activities } \\
\text { Seeks information and resources } \\
\text { Beginning to set goals for improving self-management } \\
\text { Takes accountability for health outcomes } \\
\text { Needs assistance and support to integrate behavior changes into life routines }\end{array}$ \\
\hline Level 4 & $72.5-100$ & $\begin{array}{l}\text { Partners with provider in decision making and goal setting } \\
\text { Knowledgeable about the condition and self-care activities } \\
\text { Actively seeks out information and resources to support achievement of goals } \\
\text { High confidence for self-management } \\
\text { Engaging in behaviors to meet goals to manage their health } \\
\text { May need reinforcement and support in times of stress }\end{array}$ \\
\hline
\end{tabular}


depression, anxiety, knowledge about AF, level of physical activity, and satisfaction with care) and clinical/sociodemographic (current treatment for AF, obesity, comorbidities, tobacco use, age, sex, educational level, marital status, and income level) factors are associated with activation level.

\section{Materials and methods Ethics}

We conducted a secondary analysis of prospectively collected data previously obtained for an implementation project that is described elsewhere. ${ }^{19}$ This study was approved by the Mayo Clinic Institutional Review Board and determined to be exempt because secondary analysis was performed on de-identified data and patients had provided authorization for their data to be used for research purposes.

\section{Setting and sample}

Data were collected at a Midwestern academic medical center clinic specializing in the care of patients with AF. The convenience sample included 123 patients who were 18 years of age or older with recurrent AF and who were being evaluated for an AF catheter ablation procedure from March through December 2016. Patients who were unable to communicate in English verbally and in writing, who had a documented cognitive deficit, were undergoing cancer treatment, hemodialysis, or had an implantable left ventricular assist device were excluded from the implementation project.

\section{Variables and measures}

As the main variable of interest, patient activation level was measured by the Patient Activation Measure (PAM). The PAM evaluates the patient's perceived knowledge, skills, and confidence to engage in self-management activities. Respondents report their disagreement/agreement on a Likert scale from 1 (strongly disagree) to 4 (strongly agree) to statements about managing their health. Scores were categorized according to activation levels. Table 1 presents the range of scores for each level of patient activation. ${ }^{20} \mathrm{We}$ sought to determine if sociodemographic, clinical, and patient-reported factors associated with activation in previous studies of patients with chronic illness were also associated with activation in patients with AF. We measured the following patient-reported factors: symptom burden, ${ }^{21}$ anxiety, depression, ${ }^{22}$ knowledge about $\mathrm{AF},{ }^{23}$ self-reported physical activity, ${ }^{24}$ and patient satisfaction with care ${ }^{25}$ using the instruments described in Table 2. The instrument to measure knowledge about AF was modified by removing seven questions related to warfarin use because we anticipated that a substantial portion of patients

Table 2 Characteristics of instruments to measure study variables

\begin{tabular}{|c|c|c|c|c|}
\hline Variable & Instrument & Validity evaluation & $\begin{array}{l}\text { Reliability by } \\
\text { Cronbach alpha } \\
\text { for this sample }\end{array}$ & Score range \\
\hline Patient activation & Patient Activation Measure ${ }^{20}$ & Content, construct & 0.87 & $0-100$ \\
\hline AF symptom burden & $\begin{array}{l}\text { Atrial Fibrillation Severity Scale }{ }^{21} \\
\text { Part C, items I-7 }\end{array}$ & Content, criterion & 0.90 & $0-35$ \\
\hline Anxiety & Hospital Anxiety Depression Scale ${ }^{22}$ & Content, construct & 0.88 & $\begin{array}{l}\text { 0-7 Normal } \\
\text { 8-10 Borderline } \\
\text { II-2I Anxiety }\end{array}$ \\
\hline Depression & Hospital Anxiety Depression Scale ${ }^{22}$ & Content, construct & 0.84 & $\begin{array}{l}\text { 0-7 Normal } \\
\text { 8-10 Borderline } \\
\text { II-2I Depression }\end{array}$ \\
\hline Knowledge about AF & AF Knowledge Test ${ }^{23}$ & Content & 0.87 & $0-22$ \\
\hline $\begin{array}{l}\text { Self-reported physical } \\
\text { activity (frequency and } \\
\text { intensity) }\end{array}$ & $\begin{array}{l}\text { Godin Leisure-Time Exercise } \\
\text { Questionnaire }^{24}\end{array}$ & Content, concurrent & 0.76 & $\begin{array}{l}\text { 0-no upper limit } \\
\text { Frequency multiplied by intensity of } \\
\text { exercise } \\
\text { Sample mean of } 45.5 \text { reported by authors }\end{array}$ \\
\hline $\begin{array}{l}\text { Patient satisfaction with } \\
\text { quality of care }\end{array}$ & $\begin{array}{l}\text { Patient Assessment of Chronic } \\
\text { Illness Care } \\
\text { Subscales: } \\
\text { Patient activation } \\
\text { Decision support } \\
\text { Goal setting } \\
\text { Problem solving } \\
\text { Follow-up }\end{array}$ & Content, construct & 0.94 & 20-50 Total scale \\
\hline
\end{tabular}

Abbreviation: $\mathrm{AF}$, atrial fibrillation. 
would be using direct oral anticoagulants (DOACs) instead of warfarin. The warfarin items would not be pertinent to the group using DOACs. At the time of the study, there was no psychometrically tested instrument to measure the knowledge about DOACs. To maintain consistency in the knowledge items presented to patients, we chose to focus the knowledge measurement using only the items that related to the condition of AF.

\section{Clinical and sociodemographic characteristics}

Information about the current pharmacological treatment for $\mathrm{AF}$, body mass index (BMI) as $\mathrm{kg} / \mathrm{m}^{2}$, tobacco use, systolic blood pressure at the time of the appointment, comorbidities (diabetes, hypertension, hyperlipidemia, obstructive sleep apnea, heart failure), age, sex, marital status, educational level, and third party payer were obtained from the patients' medical record.

\section{Data collection}

Patients scheduled for an evaluation for AF catheter ablation appointment were invited to participate in the implementation project to evaluate a new approach to patient education for self-management. Patients were asked to complete the PAM, Atrial Fibrillation Symptom Severity Scale, Hospital Anxiety Depression Scale (HADS), AF Knowledge test, Godin Leisure-Time Exercise Questionnaire, and Patient Assessment of Chronic Illness Care (PACIC) at the clinic site on the day of their appointment before meeting with the clinician.

\section{Data analysis}

Data were skewed and ceiling effects were common in the survey instruments. All analyses were descriptive of baseline associations. Associations between PAM levels and independent variables were examined with Fisher's exact tests for categorical variables and Kruskal-Wallis tests for continuous ones. For continuous variables, differences between activation level medians were examined using the Dwass-Steele-Critchlow-Fligner method which simultaneously performs all pairwise Wilcoxon rank-sum comparisons while adjusting for multiple testing. The level of significance was set at $P \leq 0.05$.

\section{Results}

The sample was $99 \%$ white and $66 \%$ were male. Educational attainment was high with $31.6 \%$ reporting a 4 -year college degree and $22 \%$ reporting graduate education. The mean
(SD) age was 59.9 (11.3) years with a range of 25-78 years. Forty-two percent of patients reported an annual income level of $\geq \mathrm{US} \$ 100,000$.

\section{Activation status}

At the time patients presented for their AF ablation evaluation, $84 \%$ of the sample was categorized as Level 3 (45.5\%) or $4(38 \%)$ activation categories. There was a significant difference $(P \leq 0.0001)$ among the PAM level medians. Numbers, percentages, median, and mean activation scores for each activation level are presented in Table 3.

\section{Sociodemographic and clinical characteristics associated with activation level}

As shown in Table 4, male sex, higher educational attainment, full time employment, third party payment source, and being married or in a committed relationship were associated with higher activation levels. There were a disproportionate number of men $(77 \%)$ in the Level 4 group and disproportionate number of women (73\%) in the Level 1 group. Activation levels did not differ significantly by age or income level. We observed that those in Level 1 had a higher BMI than those in Level $4(P=0.04)$ and those in Levels 1 and 2 were more likely to be current smokers than patients in Levels 3 or 4 . There were no differences in systolic blood pressure, use of rhythm controlling or heart rate controlling drugs, or comorbidities (hypertension, hyperlipidemia, diabetes, obstructive sleep apnea, heart failure) by the level of activation.

\section{Patient-reported measures associated with activation levels}

Median AF symptom burden differed among the levels. Specifically, AF symptom burden was higher in Level 1 compared to Level 4 patients $(P=0.02)$ and higher in Level 3 compared to Level $4(P=0.04)$. Symptoms of anxiety (HADS-A) showed a clear gradient by level. Although Level 1 patients reported the highest median anxiety score of 9.0, the

Table 3 Description of Patient Activation Measure levels for the sample

\begin{tabular}{llll}
\hline PAM level & $\begin{array}{l}\text { PAM mean } \\
\text { (SD) }\end{array}$ & $\begin{array}{l}\text { PAM median } \\
\text { (QI, Q3) }\end{array}$ & $\begin{array}{l}\text { Number } \\
\text { (\%) at level }\end{array}$ \\
\hline Level I & $28 . I(22.3)$ & $42.9(0.0,45 . I)$ & II (8.9) \\
Level 2 & $50.1(2.4)$ & $50.0(47.4,52.9)$ & $9(7.3)$ \\
Level 3 & $64.0(5.5)$ & $64.2(59.3,68.9)$ & $56(45.5)$ \\
Level 4 & $85.0(8.6)$ & $79.2(79.2,90.2)$ & $47(38.2)$ \\
Total & $67.8(19.2)$ & $68.9(59.3,79.2)$ & 123 \\
\hline
\end{tabular}

Abbreviation: PAM, Patient Activation Measure. 
Table 4 Sociodemographic and clinical characteristics across levels of patient activation levels

\begin{tabular}{|c|c|c|c|c|c|c|}
\hline \multirow[t]{2}{*}{ Characteristics } & \multicolumn{6}{|c|}{ Patient activation levels } \\
\hline & $I(n=I I)$ & $2(n=9)$ & $3(n=56)$ & $4(n=47)$ & Total $(\mathrm{N}=123)$ & $P$-value \\
\hline Age & & & & & & $0.485^{\mathrm{a}}$ \\
\hline Median (QI, Q3) & $62.0(58.0,73.0)$ & $64.0(54.0,69.0)$ & $61.0(52.0,68.0)$ & $61.0(52.0,69.0)$ & $61.0(53.0,69.0)$ & \\
\hline Mean (SD) & $65.3(8.2)$ & $59.4(14.6)$ & $59.3(11.0)$ & $59.5(11.7)$ & $59.9(11.3)$ & \\
\hline Sex & & & & & & $0.022^{b}$ \\
\hline Female & $8(72.7 \%)$ & $3(33.3 \%)$ & $19(34.5 \%)$ & II (23.4\%) & $4 \mathrm{I}(33.6 \%)$ & \\
\hline Male & $3(27.3 \%)$ & $6(66.7 \%)$ & $36(65.5 \%)$ & $36(76.6 \%)$ & $8 \mathrm{l}(66.4 \%)$ & \\
\hline Marital status & & & & & & $0.049^{\mathrm{b}}$ \\
\hline $\begin{array}{l}\text { Married/committed } \\
\text { relationship }\end{array}$ & 7 (77.8\%) & $5(62.5 \%)$ & $47(88.7 \%)$ & 40 (88.9\%) & 99 (86.1\%) & \\
\hline Divorced & $0(0.0 \%)$ & $2(25.0 \%)$ & $3(5.7 \%)$ & $4(8.9 \%)$ & $9(7.8 \%)$ & \\
\hline Widowed & I (II.I\%) & I (I2.5\%) & $3(5.7 \%)$ & $0(0.0 \%)$ & $5(4.3 \%)$ & \\
\hline Never married & I (II.I\%) & $0(0.0 \%)$ & $0(0.0 \%)$ & I (2.2\%) & $2(1.7 \%)$ & \\
\hline Educational attainment & & & & & & $0.004^{b}$ \\
\hline High school & $4(44.4 \%)$ & $3(33.3 \%)$ & $10(18.9 \%)$ & $3(6.5 \%)$ & $20(17.1 \%)$ & \\
\hline Some college & $3(33.3 \%)$ & 4 (44.4\%) & 15 (28.3\%) & II (23.9\%) & $33(28.2 \%)$ & \\
\hline Bachelors & I (II.I\%) & I (II.I\%) & $22(41.5 \%)$ & $13(28.3 \%)$ & 37 (31.6\%) & \\
\hline Graduate school & I (II.I\%) & I (II.I\%) & $6(11.3 \%)$ & 18 (39.1\%) & $26(22.2 \%)$ & \\
\hline Other & $0(0.0 \%)$ & $0(0.0 \%)$ & $0(0.0 \%)$ & I (2.2\%) & I (0.9\%) & \\
\hline Employment status & & & & & & $0.004^{b}$ \\
\hline Full-time & I (9.1\%) & 4 (44.4\%) & 31 (55.4\%) & 25 (53.2\%) & $6 \mathrm{I}(49.6 \%)$ & \\
\hline Part-time & $2(18.2 \%)$ & $0(0.0 \%)$ & $2(3.6 \%)$ & $6(12.8 \%)$ & $10(8.1 \%)$ & \\
\hline Retired & $4(36.4 \%)$ & $2(22.2 \%)$ & $19(33.9 \%)$ & II (23.4\%) & $36(29.3 \%)$ & \\
\hline Not working & $2(18.2 \%)$ & $3(33.3 \%)$ & I (I.8\%) & $4(8.5 \%)$ & $10(8.1 \%)$ & \\
\hline Other & $2(18.2 \%)$ & $0(0.0 \%)$ & $3(5.4 \%)$ & I (2.I\%) & $6(4.9 \%)$ & \\
\hline Household income & & & & & & $0.077^{\mathrm{b}}$ \\
\hline$<\$ 30,000$ & $2(25.0 \%)$ & $2(22.2 \%)$ & 7 (13.7\%) & $3(7.0 \%)$ & $14(12.6 \%)$ & \\
\hline$\$ 30,000$ to $\$ 59,999$ & $2(25.0 \%)$ & $3(33.3 \%)$ & $9(17.6 \%)$ & 7 (16.3\%) & 21 (I8.9\%) & \\
\hline$\$ 60,000$ to $\$ 79,999$ & $3(37.5 \%)$ & I (II.I\%) & $9(17.6 \%)$ & $3(7.0 \%)$ & $16(14.4 \%)$ & \\
\hline$\$ 80,000$ to $\$ 99,999$ & $0(0.0 \%)$ & I (II.I\%) & $8(15.7 \%)$ & $4(9.3 \%)$ & 13 (II.7\%) & \\
\hline$\$ 100,000$ or more & $\mathrm{I}(12.5 \%)$ & $2(22.2 \%)$ & $18(35.3 \%)$ & $26(60.5 \%)$ & 47 (42.3\%) & \\
\hline Insurance & & & & & & $0.042^{\mathrm{b}}$ \\
\hline Government & $5(45.5 \%)$ & $2(22.2 \%)$ & $14(25.0 \%)$ & $8(17.0 \%)$ & $29(23.6 \%)$ & \\
\hline Private & $3(27.3 \%)$ & $6(66.7 \%)$ & $36(64.3 \%)$ & 37 (78.7\%) & $82(66.7 \%)$ & \\
\hline Other & $3(27.3 \%)$ & I (II.I\%) & $6(10.7 \%)$ & $2(4.3 \%)$ & $12(9.8 \%)$ & \\
\hline Hispanic & & & & & & $0.554^{b}$ \\
\hline Yes & $0(0.0 \%)$ & $0(0.0 \%)$ & $0(0.0 \%)$ & I (2.2\%) & I (0.9\%) & \\
\hline No & $10(100.0 \%)$ & $7(100.0 \%)$ & $50(100.0 \%)$ & 44 (97.8\%) & III (99.1\%) & \\
\hline Race & & & & & & $1.000^{\mathrm{b}}$ \\
\hline White & $10(100.0 \%)$ & $9(100.0 \%)$ & $50(98.0 \%)$ & 45 (100.0\%) & II 14 (99.1\%) & \\
\hline American Indian or Alaska & $0(0.0 \%)$ & $0(0.0 \%)$ & I (2.0\%) & $0(0.0 \%)$ & I (0.9\%) & \\
\hline Native & & & & & & \\
\hline BMI $\left(\mathrm{kg} / \mathrm{m}^{2}\right)$ & & & & & & $0.028^{a}$ \\
\hline Median (QI, Q3) & $33.5(29.2,40.4)$ & $28.2(26.4,32.8)$ & $30.2(27.5,35.2)$ & $28.2(25.4,32.4)$ & $29.3(27.1,34.6)$ & \\
\hline Mean (SD) & $35.0(7.7)$ & $29.6(4.7)$ & $32.3(8.0)$ & $28.8(4.8)$ & $31.0(6.9)$ & \\
\hline Smoking status & & & & & & $0.017^{\mathrm{b}}$ \\
\hline Current & $2(22.2 \%)$ & $3(33.3 \%)$ & $3(6.4 \%)$ & $2(5.0 \%)$ & $10(9.5 \%)$ & \\
\hline Past & $2(22.2 \%)$ & $4(44.4 \%)$ & $20(42.6 \%)$ & $9(22.5 \%)$ & $35(33.3 \%)$ & \\
\hline Never & $5(55.6 \%)$ & $2(22.2 \%)$ & $24(51.1 \%)$ & $29(72.5 \%)$ & $60(57.1 \%)$ & \\
\hline Systolic blood pressure & & & & & & $0.412^{\mathrm{a}}$ \\
\hline Median (QI, Q3) & $127.0(\mid 18.0,137.0)$ & $122.0(\mid 10.0,145.0)$ & $123.0(|| 2.5, \mid 36.5)$ & $120.0(109.0,124.0)$ & $121.0(|| \mid .0,134.0)$ & \\
\hline Mean (SD) & $129.4(18.3)$ & $126.7(26.8)$ & I24.I (I5.2) & $119.4(15.4)$ & $123.0(16.7)$ & \\
\hline Antiarrhythmic medication & & & & & & $0.643^{b}$ \\
\hline Yes & $4(36.4 \%)$ & $3(33.3 \%)$ & 17 (30.4\%) & $20(42.6 \%)$ & $44(35.8 \%)$ & \\
\hline No & $7(63.6 \%)$ & $6(66.7 \%)$ & $39(69.6 \%)$ & 27 (57.4\%) & 79 (64.2\%) & \\
\hline Heart rate control medication & & & & & & $0.24 I^{b}$ \\
\hline Yes & $6(54.5 \%)$ & 7 (77.8\%) & $35(62.5 \%)$ & $22(46.8 \%)$ & 70 (56.9\%) & \\
\hline No & $5(45.5 \%)$ & $2(22.2 \%)$ & $21(37.5 \%)$ & $25(53.2 \%)$ & $53(43.1 \%)$ & \\
\hline
\end{tabular}


Table 4 (Continued)

\begin{tabular}{|c|c|c|c|c|c|c|}
\hline \multirow[t]{2}{*}{ Characteristics } & \multicolumn{6}{|c|}{ Patient activation levels } \\
\hline & $I(n=I I)$ & $2(n=9)$ & $3(n=56)$ & $4(n=47)$ & Total $(\mathrm{N}=123)$ & $P$-value \\
\hline \multicolumn{7}{|l|}{ Comorbidities } \\
\hline Diabetes & $2(18.2 \%)$ & I (II.I\%) & $4(7.1 \%)$ & $6(12.8 \%)$ & $13(10.6 \%)$ & $0.4404^{b}$ \\
\hline Hypertension & $6(54.5 \%)$ & 7 (77.8\%) & $28(50.0 \%)$ & $22(46.8 \%)$ & $63(51.2 \%)$ & $0.2569^{\mathrm{b}}$ \\
\hline Hyperlipidemia & $3(27.3 \%)$ & 4 (44.4\%) & $19(33.9 \%)$ & $19(40.4 \%)$ & $45(36.6 \%)$ & $0.8926^{\mathrm{b}}$ \\
\hline Obstructive sleep apnea & $5(45.5 \%)$ & $3(33.3 \%)$ & $28(50.0 \%)$ & $14(29.8 \%)$ & $50(40.7 \%)$ & $0.2066^{\mathrm{b}}$ \\
\hline Heart failure & I (9.1\%) & $0(0.0 \%)$ & $2(3.6 \%)$ & $2(4.3 \%)$ & $5(4.1 \%)$ & $0.632 \mathrm{I}^{\mathrm{b}}$ \\
\hline
\end{tabular}

Notes: ${ }^{a}$ Kruskal Wallis; ${ }^{b}$ Fisher Exact

Abbreviation: BMI, Body Mass Index.

significant difference in median anxiety scores was observed between Level 3 (HADS-A =6) and Level 4 (HADS-A =3). Symptoms of depression (HADS-D) also differed among levels with depression scores decreasing as activation level increased. Level 4 patients reported fewer depression symptoms than patients in Levels $1(P=0.0002), 2(P=0.02)$, and $3(P=0.0002)$, and Level 3 patients reported significantly fewer depression symptoms than Level $1(P=0.02)$. We also observed a difference in levels for AF knowledge. Patients in Level 1 scored lower on the Knowledge about Atrial Fibrillation test compared to those in Level $4(P=0.02)$. Selfreported physical activity differed among levels $(P=0.02)$, with Level 4 patients reporting significantly $(P=0.04)$ higher scores compared to Level 3 patients. Although the analysis of the PACIC subscale for patient activation was significant for an overall difference among levels $(P=0.03)$, tests for multiple comparison showed nonsignificant findings for differences between Levels 2 and $4(P=0.06)$ and Levels 3 and $4(P=0.08)$. Otherwise, there were no significant differences in PACIC subscale scores among the four levels (Table 5).

\section{Discussion}

This investigation identifies several important elements within the sphere of patient activation in the context of symptomatic AF. These findings characterize this cohort of patients to exhibit fairly substantial activation, and also provide key insights into modifiable factors to improve this vital element.

\section{Activation levels}

The proportion of patients in activation Levels 3 (46\%) and $4(38 \%)$ was higher in this sample compared with some other reports. To our knowledge, patient activation has not been reported in patients with AF, but two studies examined the distribution of activation levels in patients hospitalized with heart failure. Creber et $\mathrm{al}^{26}$ reported that in their sample,
$39 \%$ and $26 \%$ were at Levels 3, and 4, respectively, and Dunlay et al reported that $40 \%$ were identified as Level 3 and only $3 \%$ as Level $4 .{ }^{11}$ Bos-Touwen et al observed that in 1,154 patients with common chronic illnesses, half were at activation Levels 1 and 2 and only a minority of patients with HF (11\%), diabetes (13\%), COPD (14\%), or chronic renal disease $(8 \%)$ were at activation Level $4 .{ }^{12}$ Results more similar to ours were reported by Greene and Hibbard who examined a database of 25,047 Midwestern individuals with at least one chronic condition where $46 \%, 33 \%, 14 \%$, and $7 \%$ were in activation Levels $4,3,2$, and 1 , respectively. ${ }^{9}$ The mean (SD) PAM score for our sample was 67.8 (19.2) which was considerably higher compared to mean scores of patients with common chronic illnesses which ranged from $51.4(10.0)^{6}$ to $55.3(11.0) .^{12}$

The higher activation level in our sample may be explained by the fact that patients seeking evaluation for catheter ablation often have had multiple prior encounters with clinicians for their condition. Thereby, this patient cohort seeking ablation may have been exposed to considerable information about AF either during clinical encounters or by visiting Internet sites about their condition. Some patients self-refer after gathering information about centers for arrhythmia care. Those who self-refer may possess more characteristics of activation. The finding that nearly half (46\%) of patients in this sample were at Level 3 activation level is encouraging because at Level 3, patients have developed some motivation to make changes to benefit their health, ${ }^{5}$ and in the case of ablation patients, reduce the progression of AF. Previous research has established that engaging in activities to improve cardiopulmonary fitness and reduce weight significantly reduce recurrence of $\mathrm{AF}$ after ablation..$^{15-17}$ Thus, the time surrounding ablation is a critical time for engaging in cognitive and behavioral interventions with patients who show readiness for change and to reinforce and support the changes they are currently contemplating or have begun. 
Table 5 Patient-reported outcomes across patient activation levels

\begin{tabular}{|c|c|c|c|c|c|c|}
\hline \multirow{2}{*}{$\begin{array}{l}\text { Patient-reported } \\
\text { outcomes }\end{array}$} & \multicolumn{6}{|c|}{ Levels of patient activation } \\
\hline & $I(n=I I)$ & $2(n=9)$ & $3(n=56)$ & $4(n=47)$ & Total $(\mathbf{N}=123)$ & $P$-value \\
\hline AFSS & & & & & & $0.006^{\mathrm{a}}$ \\
\hline Median (QI, Q3) & $16(14.0,22.0)$ & $12(6.0,17.0)$ & $13(8.5,18.0)$ & $9(6.0,14.0)$ & $12(7.0,17.0)$ & \\
\hline Mean (SD) & $17.9(8.3)$ & I I.8 (7.4) & $13.5(6.8)$ & $10.0(6.4)$ & $12.4(7.1)$ & \\
\hline HADS: Anxiety & & & & & & $0.006^{\mathrm{a}}$ \\
\hline Median (QI, Q3) & $9(3.0,11.0)$ & $7(5.5,7.5)$ & $6(4.0,8.0)$ & $3(2.0,7.0)$ & $6(3.0,8.0)$ & \\
\hline Mean (SD) & $8.2(5.2)$ & $7.8(4.3)$ & $6.0(3.3)$ & $4.3(3.0)$ & $5.7(3.6)$ & \\
\hline HADS: Depression & & & & & & $<0.00 I^{a}$ \\
\hline Median (QI, Q3) & $6.5(6.0,8.0)$ & $6(3.0,8.0)$ & $5(2.0,6.0)$ & $2(0.0,3.0)$ & $3(2.0,6.0)$ & \\
\hline Mean (SD) & $7.8(4.0)$ & $5.9(3.1)$ & $4.4(2.4)$ & $2.5(2.8)$ & $4.0(3.2)$ & \\
\hline Knowledge of $\mathrm{AF}$ & & & & & & $0.013^{\mathrm{a}}$ \\
\hline Median (QI, Q3) & $15(4.0,17.0)$ & $17(15.0,19.0)$ & $17(14.0,19.0)$ & $18(16.0,20.0)$ & $17(15.0,19.0)$ & \\
\hline Mean (SD) & II.5 (7.3) & $16.6(3.4)$ & I6.I (4.0) & $17.7(2.6)$ & $16.3(4.2)$ & \\
\hline GLTEQ & & & & & & $0.023^{\mathrm{a}}$ \\
\hline Median (QI, Q3) & $0(0.0,44.0)$ & $27(|2.0,4| .0)$ & $20.5(9.0,37.0)$ & $32(21.0,48.0)$ & $25(12.0,44.0)$ & \\
\hline Mean (SD) & I $8.5(24.7)$ & $31.9(27.5)$ & $32.6(49.1)$ & $39.8(33.6)$ & $34.0(40.6)$ & \\
\hline PACIC: Patient activation & & & & & & $0.029^{a}$ \\
\hline Median (QI, Q3) & $3.3(2.0,5.0)$ & $3(2.2,3.8)$ & $3.7(2.7,4.3)$ & $4.3(3.3,5.0)$ & $3.7(3.0,4.7)$ & \\
\hline Mean (SD) & $3.3(1.6)$ & $3.0(1.0)$ & $3.5(1.2)$ & $4.0(1.0)$ & $3.6(1.2)$ & \\
\hline PACIC: Decision support & & & & & & $0.075^{\mathrm{a}}$ \\
\hline Median (QI, Q3) & $3.2(2.3,4.3)$ & $3.3(2.0,4.0)$ & $3.2(2.3,4.0)$ & $3.7(3.0,4.7)$ & $3.3(2.3,4.3)$ & \\
\hline Mean (SD) & $3.3(1.2)$ & $3.1(1.1)$ & $3.2(I . I)$ & $3.7(1.0)$ & $3.4(I . I)$ & \\
\hline PACIC: Goal setting & & & & & & $0.123^{a}$ \\
\hline Median (QI, Q3) & $2.3(1.6,3.8)$ & $2.4(2.0,2.8)$ & $2.2(1.6,3.2)$ & $2.8(2.2,3.4)$ & $2.4(1.8,3.2)$ & \\
\hline Mean (SD) & $2.5(1.2)$ & $2.3(0.6)$ & $2.4(1.0)$ & $2.8(1.0)$ & $2.5(1.0)$ & \\
\hline PACIC: Problem solving & & & & & & $0.118^{\mathrm{a}}$ \\
\hline Median (QI, Q3) & $1.8(1.3,3.5)$ & $3(1.5,3.8)$ & $3(2.1,4.0)$ & $3.6(2.5,4.5)$ & $3.1(2.0,4.0)$ & \\
\hline Mean (SD) & $2.5(1.4)$ & $2.8(1.2)$ & $3.0(1.2)$ & $3.4(1.2)$ & $3.1(1.3)$ & \\
\hline PACIC: Follow-up & & & & & & $0.418^{\mathrm{a}}$ \\
\hline Median (QI, Q3) & $2(1.2,3.6)$ & $1.4(1.2,1.8)$ & $1.6(1.2,2.6)$ & $1.9(1.4,2.5)$ & $1.8(1.2,2.6)$ & \\
\hline Mean (SD) & $2.3(1.3)$ & $1.6(0.7)$ & $2.0(1.0)$ & $2.2(1.0)$ & $2.1(1.0)$ & \\
\hline PACIC: Overall & & & & & & $0.068^{\mathrm{a}}$ \\
\hline Median (QI, Q3) & $2.2(1.9,4.0)$ & $2.9(1.8,3.0)$ & $2.5(2.1,3.4)$ & $3.1(2.4,3.7)$ & $2.7(2.1,3.5)$ & \\
\hline Mean (SD) & $2.7(I . I)$ & $2.4(0.7)$ & $2.7(0.9)$ & $3.1(0.9)$ & $2.8(1.0)$ & \\
\hline
\end{tabular}

Note: ${ }^{a}$ Kruskal-Wallis test.

Abbreviations: AF, atrial fibrillation; AFSS, Atrial Fibrillation Severity Scale; GLTEQ, Godin Leisure-Time Exercise Questionnaire; HADS, Hospital Anxiety Depression Scale; PACIC, Patient Assessment of Chronic Illness Care.

\section{Sociodemographic and clinical characteristics associated with activation level}

Our findings that higher levels of activation are associated with higher educational attainment are consistent with previous reports. ${ }^{6,11,12,27,28}$ Compared to other investigations that have shown older age to be associated with lower activation, ${ }^{6,11,13,27}$ age was not associated with activation level in our sample. Findings regarding sex and activation have been mixed with some studies finding no association between sex and activation level..$^{711,12,26}$ Our results demonstrating that males were more likely to be categorized as Levels 3 or 4 are consistent with those of Magnezi et $\mathrm{al}^{29}$ and Hendriks et al, ${ }^{6}$ but opposite to that reported by Hibbard et $\mathrm{al}^{1}$ and Aung et $\mathrm{al}^{27}$ who observed that males were less likely to be categorized in Levels 3 or 4. Our findings concerning the relationship between employment and activation were similar to Aung et al, ${ }^{27}$ who reported that compared to participants in activation Levels 1 and 2, those in Levels 3 and 4 were more likely to be employed full or part time. Some investigators have reported a positive relationship between higher income and activation level. ${ }^{12,27}$ In our sample, there was no statistically significant difference for activation among income levels.

Similar to other studies, ${ }^{1,8-10,12}$ we observed that increased BMI was associated with lower activation levels. Obesity is a major contributor to the recurrence of $\mathrm{AF}$ after catheter ablation, ${ }^{17}$ and as our sample reflects, being overweight or obese is a common characteristic of AF patients. ${ }^{13}$ Identifying 
the activation level of overweight and obese patients provides guidance to clinicians for tailoring the approach to weight loss interventions. Patients who are in Levels 1 and 2 may need more education about AF and obesity and coaching to promote readiness to take accountability for weight loss behaviors, whereas patients at Level 3 who are ready to make changes may need assistance with goal setting and resources to support weight loss activities. Level 4 patients may simply need reinforcement and affirmation for their success in continuing to work toward their goals.

\section{Patient-reported factors associated with activation}

Patients in Level 1 reported significantly more symptom burden compared to those in Level 4. We know of no published reports about the relationship between symptoms and activation in patients with AF; however, symptom burden in AF has been shown to be associated more with perceptual factors (illness perception, coping strategies, ${ }^{30}$ depressed mood, anxiety, somatization ${ }^{31}$ ) and not always objective factors such as the actual presence or absence of AF. ${ }^{32}$ It is possible that individuals who do not feel engaged and activated may perceive their symptoms differently than those who believe they have a part in managing symptoms. ${ }^{30}$ Management of symptoms is a high priority for AF treatment and controlling health care costs. Further study is warranted to explain the relationship between $\mathrm{AF}$ symptom perception and patient activation and to examine how interventions to improve activation influence symptom burden.

Psychological distress is commonly reported by patients with AF. Investigators have documented that 29\%-60\% of participants studied reported scores consistent with anxiety, ${ }^{33-35}$ and 20\%-56\% reported scores consistent with depression. ${ }^{33,34,36}$ The percentages of patients in our sample reporting scores for anxiety (11\%) and depression (4\%) considered abnormal (score of 11-21) on the HADS were much lower than the studies noted earlier. Yet both anxiety and depression were associated with activation levels, with lower activation levels reporting more symptoms of anxiety and depression. Although reports of the relationship between anxiety and patient activation are rare, the association of increased symptoms of depression with lower levels of activation has been observed consistently across chronic conditions..$^{8,9,12,29}$ The presence of depression should alert the clinician that the patient may be at risk for low activation status. The consistent nature of the activation-depression relationship is clinically relevant because although no causal relationship can be assumed, treatment of depression may promote affective responses that will foster progress to a higher activation level. These findings highlight the importance of integrating screenings for depression and anxiety into routine care for people with chronic illness. Although our findings about the relationship between psychological distress and patient activation support those of previous studies, to our knowledge, this is the first investigation to document this relationship in AF patients. Further study is needed to determine if such a relationship exists in a more diverse sample of AF patients who are treated outside of a referral center.

Knowledge about the chronic illness and its treatment is an important component of self-management and activation. ${ }^{5}$ Our finding of a positive relationship between knowledge of AF and activation extends findings of others who reported that greater knowledge about the chronic illness and recommended self-care activities were related to higher activation. 2,6 These results are clinically relevant because they affirm that providing patients with education about the condition and recommended self-care equips them with the knowledge they need as a foundation to move up the activation continuum.

Although the relationship between physical activity and activation has not been widely reported, we considered it important to explore that relationship. Engaging in physical activity and increased cardiopulmonary fitness are linked to reduced AF recurrence after ablation. ${ }^{15}$ There were a large range of physical activity scores across all levels in our sample; some patients in all levels reported 0 values, which reflect an opportunity for improving physical activity even in the most activated patients. We did observe that the median physical activity score for Level 1 patients was 0 , reflecting that $50 \%$ of those reported a score of 0 . As expected, the most activated patients (Level 4) reported higher levels of physical activity than those from other levels. These results are consistent with the few other studies where activation and physical activity were measured. ${ }^{2,26}$

An unexpected finding was the lack of a significant relationship between the total PACIC and PACIC subscale scores and patient activation. Items in the PACIC measure the patients' perception of quality of care including the clinician's ability to engage the patient in self-management activities and treatment decisions, work with the patient in goal setting and problem solving, and the extent to which the clinician offers resources to support self-management and facilitates appropriate follow-up. One might expect that patients who are the most satisfied with their clinician's performance on the activities measured by the PACIC would 
report higher activation scores. Our findings show a trend for support of that expectation, but no statistical difference among the levels. Other investigators have observed a positive relationship between PAM and PACIC scores. ${ }^{27,28}$ It is possible that we did not find any significant difference among the scores because of the lack of variability in PACIC scores. We did observe that even patients in Level 1 of our sample reported higher mean satisfaction scores for the total PACIC and Activation, Decision Support and Goal Setting subscales than the 266 managed care patients who constituted the sample in a study to validate the PACIC. ${ }^{25}$ Further study of the relationship between satisfaction with the quality of care and patient activation in a diverse sample is needed to determine the nature of this relationship in patients with AF.

\section{Limitations}

Even though most of our findings are consistent with those previously reported, there are limitations that should be considered when interpreting the results. The instrument to measure knowledge about AF did not contain items related to anticoagulation. Thus, the association between knowledge about anticoagulation, an important aspect of AF self-management, and level of activation was not tested. The sample was homogeneous in terms of race and ethnicity with an education and income level higher, and the mean age lower than the general population of AF patients. The sample was one of convenience and comprised of symptomatic patients evaluated at an arrhythmia specialty clinic who were seeking an advanced treatment for recurrent AF. Thus, the results should not be generalized to the general population of patients with AF, particularly those whose AF may not warrant consideration for ablation treatment or those who decide to manage AF with pharmacological therapy. The data were collected from patients at one single Midwest academic center; nevertheless, because of referrals, patients came from settings across the US and had been cared for by providers other than providers at the data collection site. The cross-sectional descriptive design reveals only associations between activation and study variables, while no assumptions of causation can be made. The small percentage of patients who fall into Levels 1 and 2 activation limits the information that can be garnered, even with appropriate statistical methodology to account for this.

\section{Conclusion}

In this sample of patients seeking advanced treatment for symptomatic AF, we observed a high level of activation, indicating that the majority were knowledgeable about their
AF, were ready to or already had begun to make lifestyle changes to improve their health, and possessed a sufficient level of confidence to self-manage their health. Further research with larger and more diverse samples is needed to gain a broader understanding of patient activation in the growing population of patients with AF. Higher levels of patient activation were also associated with a more positive health status. Our findings advance the knowledge about levels of activation in patients with $\mathrm{AF}$ and factors associated with activation that can be used to inform interventions to improve self-management and identify those at risk for low activation and poorer outcomes. As the evidence mounts regarding the importance of managing risk factors such as obesity, hypertension, physical inactivity, and obstructive sleep apnea to reduce AF progression, further research is needed to develop and test interventions to promote high levels of activation that are associated with positive health behaviors.

\section{Acknowledgments}

We would like to acknowledge Dr Francis C Nichols, Dr Thomas M Munger, Ms Amanda Attaway, Ms Shelley Rasmusson, Ms Teresa Johnson, Ms Ashley Baker, Ms Ashley V Pitzer, and Ms Meghan French for their support, dedication, and assistance throughout this project. We are also extremely grateful to all of the project's participants. Funding for this study was provided by the Robert D. and Patricia E. Kern Center for the Science of Health Care Delivery, Mayo Clinic.

\section{Disclosure}

The authors report no conflicts of interest in this work.

\section{References}

1. Hibbard JH, Greene J, Sacks RM, Overton V, Parrotta C. Improving population health management strategies: identifying patients who are more likely to be users of avoidable costly care and those more likely to develop a new chronic disease. Health Serv Res. 2017;52(4): 1297-1309.

2. Hibbard JH, Greene J, Shi Y, Mittler J, Scanlon D. Taking the long view: how well do patient activation scores predict outcomes four years later? Med Care Res Review: MCRR. 2015;72(3):324-337.

3. Shively MJ, Gardetto NJ, Kodiath MF, et al. Effect of patient activation on self-management in patients with heart failure. J Cardiovasc Nurs. 2013;28(1):20-34.

4. Buttorff C, Ruder T, Bauman M. Multiple chronic conditions in the United States. 2017. Available from: https://www.rand.org/pubs/tools/ TL221.html. Accessed April 16, 2018.

5. Hibbard JH, Stockard J, Mahoney ER, Tusler M. Development of the Patient Activation Measure (PAM): conceptualizing and measuring activation in patients and consumers. Health Serv Res. 2004;39(4 Pt 1) 1005-1026.

6. Hendriks M, Rademakers J. Relationships between patient activation, disease-specific knowledge and health outcomes among people with diabetes; a survey study. BMC Health Serv Res. 2014;14:393. 
7. Peters AE, Keeley EC. Patient engagement following acute myocardial infarction and its influence on outcomes. Am J Cardiol. 2017;120(9): 1467-1471.

8. Sacks RM, Greene J, Hibbard JH, Overton V. How well do patient activation scores predict depression outcomes one year later? J Affect Disord. 2014;169:1-6.

9. Greene J, Hibbard JH. Why does patient activation matter? An examination of the relationships between patient activation and health-related outcomes. J Gen Intern Med. 2012;27(5):520-526.

10. Greene J, Hibbard JH, Sacks R, Overton V, Parrotta CD. When patient activation levels change, health outcomes and costs change, too. Health Aff. 2015;34(3):431-437.

11. Dunlay SM, Griffin JM, Redfield MM, Roger VL. Patient activation in acute decompensated heart failure. J Cardiovasc Nurs. 2017;32(6): $560-567$.

12. Bos-Touwen I, Schuurmans M, Monninkhof EM, et al. Patient and disease characteristics associated with activation for self-management in patients with diabetes, chronic obstructive pulmonary disease, chronic heart failure and chronic renal disease: a cross-sectional survey study. PLoS One. 2015;10(5):e0126400.

13. Kirchhof P, Benussi S, Kotecha D, et al. 2016 ESC Guidelines for the management of atrial fibrillation developed in collaboration with EACTS: The Task Force for the management of atrial fibrillation of the European Society of Cardiology (ESC)Developed with the special contribution of the European Heart Rhythm Association (EHRA) of the ESC Endorsed by the European Stroke Organisation (ESO). Europace. Epub 2016 Aug 28.

14. Delaney J, Yin X, Fontes J, et al. Hospital and clinical care costs associated with atrial fibrillation for Medicare benificaries in the Cardiovascular Health Study and the Framingham Study. Sage Open Medicine. 2018;6:1-9.

15. Malmo V, Nes BM, Amundsen BH, et al. Aerobic Interval Training Reduces the Burden of Atrial Fibrillation in the Short Term. Circulation. 2016;133(5):466-473.

16. Pathak RK, Middeldorp ME, Lau DH, et al. Aggressive risk factor reduction study for atrial fibrillation and implications for the outcome of ablation. J Am Coll Cardiol. 2014;64(21):2222-2231.

17. Pathak RK, Middeldorp ME, Meredith M, et al. Long-term effect of goal-directed weight management in an atrial fibrillation cohort: A long-term follow-up study (LEGACY). J Am Coll Cardiol. 2015;65(20): 2159-2169.

18. Langseth MS, Shepherd E, Thomson R, Lord S. Quality of decision making is related to decision outcome for patients with cardiac arrhythmia. Patient Educ Couns. 2012;87(1):49-53.

19. Griffin JM, Stuart Mullen L, Schmidt M, et al. The evaluation and implementation of shared medical appointments to improve selfmanagement, knowledge and care quality among patients with atrial fibrillation: REDUCE AF. Mayo Clinic Proceedings: Innovations, Quality \& Outcomes. 2018:2(3):218-225.

20. Hibbard JH, Mahoney ER, Stockard J, Tusler M. Development and testing of a short form of the patient activation measure. Health Serv Res. 2005;40(6Pt1):1918-1930.
21. Dorian P, Paquette M, Newman D, et al. Quality of life improves with treatment in the Canadian Trial of Atrial Fibrillation. Am Heart $J$. 2002;143(6):984-990.

22. Bjelland I, Dahl A, Haug T. The validity of the Hospital Anxiety and Depression Scale. An updated literature review. J Psychosomat Res. 2002;52:69-77.

23. Koponen L, Rekola L, Ruotsalainen T, Lehto M, Leino-Kilpi H, VoipioPulkki L-M. Patient knowledge of atrial fibrillation: 3-month follow-up after an emergency room visit. $J$ Adv Nurs. 2008;61(1):51-61.

24. Godin G, Shepard R. A simple method to assess behavior in the community. Can J Applie Sport Science. 1985;10(3):141-146.

25. Glasgow RE, Wagner EH, Schaefer J, Mahoney LD, Reid RJ, Greene SM. Development and Validation of the Patient Assessment of Chronic Illness Care (PACIC). Med Care. 2005;43(5):436-444.

26. Creber R, Chen T, Wei C, Lee CS. Brief report: Patient activation among urban hosptalized patients with heart failure. J Cardiac Fail. 2017;23(11):817-820.

27. Aung E, Donald M, Coll JR, Williams GM, Doi SAR. Association between patient activation and patient-assessed quality of care in type 2 diabetes: results of a longitudinal study. Health Expectations. 2016;19(2): 356-366.

28. Alegría M, Sribney W, Perez D, Laderman M, Keefe K. The role of patient activation on patient-provider communication and quality of care for us and foreign born Latino patients. J Gen Intern Med. 2009;24(S3):534-541.

29. Magnezi R, Glasser S, Shalev H, Sheiber A, Reuveni H. Patient activation, depression and quality of life. Patient Educ Couns. 2014;94(3):432-437.

30. McCabe PJ, Barnason SA. Illness perceptions, coping strategies, and symptoms contribute to psychological distress in patients with recurrent symptomatic atrial fibrillation. $J$ Cardiovasc Nurs. 2012;27(5):431-444.

31. Gehi AK, Sears S, Goli N, et al. Psychopathology and symptoms of atrial fibrillation: implications for therapy. J Cardiovasc Electrophysiol. 2012;23(5):473-478.

32. Sears SF, Serber EVAR, Alvarez LG, Schwartzman DS, Hoyt RH, Ujhelyi MR. Understanding atrial symptom reports: objective versus subjective predictors. Pacing and Clinical Electrophysiology. 2005;28(8):801-807.

33. Bostrom JA, Saczynski JS, Hajduk A, et al. Burden of psychosocial and cognitive impairment in patients with atrial fibrillation. Critical Pathways in Cardiology. 2017;16(2):71-75.

34. Polikandrioti M, Koutelekos I, Vasilopoulos G, et al. Anxiety and depression in patients with permanent atrial fibrillation: prevalence and associated factors. Cardiol Res Prac. 2018; Volume 2018, Article ID 7408129, 9 pages.

35. Serpytis R, Navickaite A, Serpytiene E, et al. Impact of atrial fibrillation on cognitive function, psychological distress, quality of life and impulsiveness. Am J Med. 2018;131(6):703.e1-703.e5.

36. Thompson TS, Barksdale DJ, Sears SF, Mounsey JP, Pursell I, Gehi AK. The effect of anxiety and depression on symptoms attributed to atrial fibrillation. Pacing and Clinical Electrophysiology. 2014;37(4):439-446.
Patient Preference and Adherence

\section{Publish your work in this journal}

Patient Preference and Adherence is an international, peer-reviewed, open access journal that focuses on the growing importance of patient preference and adherence throughout the therapeutic continuum. Patient satisfaction, acceptability, quality of life, compliance, persistence and their role in developing new therapeutic modalities and compounds to optimize

\section{Dovepress}

clinical outcomes for existing disease states are major areas of interest for the journal. This journal has been accepted for indexing on PubMed Central. The manuscript management system is completely online and includes a very quick and fair peer-review system, which is all easy to use. Visit http://www. dovepress.com/testimonials.php to read real quotes from published authors. 